\title{
Detection of Ureaplasma Biovars and Subtyping of Ureaplasma parvum among Women Referring to a University Hospital in Morocco
}

\author{
Safae Karim, ${ }^{1}$ Chahrazed Bouchikhi, ${ }^{2,3}$ Abdelaziz Banani, ${ }^{2}$ Hinde E. L. Fatemi, ${ }^{4}$ \\ Tiatou Souho, ${ }^{1}$ Sanaa Erraghay, ${ }^{2}$ and Bahia Bennani $\mathbb{D}^{1,3}$ \\ ${ }^{1}$ Laboratoire de Microbiologie et de Biologie Moléculaire, Faculté de Médecine et de Pharmacie de Fès (FMPF), Université Sidi \\ Mohammed Ben Abdellah (USMBA), Fès, Morocco \\ ${ }^{2}$ Service de Gynécologie CHU Hassan II de Fès, Morocco \\ ${ }^{3}$ Equipe Micro-organismes, Génomique et Facteurs Oncogènes, Laboratoire de Pathologie Humaine, Biomédecine et Environnement, \\ FMPF, USMBA, Fès, Morocco \\ ${ }^{4}$ Equipe Anatomo-Pathology, Laboratoire Central d'Analyse Médicale, CHU Hassan II, Fès, Morocco
}

Correspondence should be addressed to Bahia Bennani; bahia.bennani@usmba.ac.ma

Received 19 March 2020; Accepted 22 May 2020; Published 8 June 2020

Academic Editor: Bryan Larsen

Copyright (C) 2020 Safae Karim et al. This is an open access article distributed under the Creative Commons Attribution License, which permits unrestricted use, distribution, and reproduction in any medium, provided the original work is properly cited.

\begin{abstract}
Objectives. The aim of this study was to determine the prevalence of Ureaplasma biovars and Ureaplasma parvum (U. parvum) serovars, their associated risk factors, and genital STI-related symptoms. Methods. DNA obtained from cervical samples of 1053 women attending the department of Obstetrics and Gynecology and the laboratory of pathological anatomy of Hassan II university hospital of Fez, Morocco, was used to detect Ureaplasma biovars (U. urealyticum and U. parvum) and to subtype U. parvum by polymerase chain reaction (PCR). Results. Of the 1053 women examined, 25.4\% (268/1053) were Ureaplasma positives. The rates of $U$. urealyticum and $U$. parvum were $12.1 \%(128 / 1053)$ and $7 \%(74 / 1053)$, respectively, and the copresence of these biovars was noted in $6.3 \%(66 / 1053)$ cases. The $U$. parvum subtyping revealed a predominance of the serovar $3 / 14$ (61.4\%). The association of demographics variables with Ureaplasma biovars was studied and shows that the age (" $<30$ " years) seems to be a risk factor of Ureaplasma spp. and U. urealyticum carriage (OR 1.729, 95\% CI [1.113-2.687] and OR 1.848, 95\% CI [1.026-3.330], respectively). There was no difference in the prevalence of Ureaplasma type regarding symptoms. However, a significant association was found between $U$. parvum serovar 1 and infertility $(P=0.011)$. Conclusion. This first study conducted in Morocco provides an idea on Ureaplasma biovars and $U$. parvum serovars circulating in this region, their associated risk factors, and genital STI-related symptoms. Therefore, further studies are required to clarify and confirm the pathogenic role of these Ureaplasma species.
\end{abstract}

\section{Introduction}

Urogenital Ureaplasma belongs to the normal commensal flora of the human genital tract $[1,2]$. However, it can be pathogenic when its bacterial load is $\geq 10^{4}$ organisms per $\mathrm{ml}$ (infectious dose). This rate is commonly accepted as a burden indicating an infection that should be treated $[2,3]$. In fact, it can be associated with many gynaecological or obstetric pathologies such as nongonococcal urethritis, pelvic inflammatory disease, premature birth or late abortion, and infertility [4].
Human Ureaplasma spp. include two human pathogen species: Ureaplasma urealyticum (U. urealyticum) (biovar 2 ) and Ureaplasma parvum (U. parvum) (biovar 1). The specific identification of each species is based on molecular methods [5], and some studies shows that $U$. parvum is more common than the most pathogenic $U$. urealyticum [6]. The colonization rate in healthy women is about $18-87 \%$ for U. parvum and about $6-10 \%$ for U. urealyticum [7].

Based on biochemical and genetic characteristics [5], $U$. parvum (parvo biovar) is divided on four serovars $(1,3,6$, 
Table 1: Primers used in this study.

\begin{tabular}{|c|c|c|c|c|}
\hline Species & Primer (forward and reverse) & Sequence $\left(5^{\prime}-3^{\prime}\right)$ & Size (bp) & Reference \\
\hline \multirow{2}{*}{ U. urealyticum } & \multirow{2}{*}{ ureA-B } & GAA ACG ACG TCC ATA AGC AAC T & \multirow{2}{*}{423} & \multirow{2}{*}[17]{} \\
\hline & & GCA ATC TGC TCG TGA AGT ATT AC & & \\
\hline \multirow{2}{*}{ U. parvum } & UMS-57 & (T/C)AA ATC TTA GTG TTC ATA TTT TTT AC & \multirow{2}{*}{$326 / 327$} & \\
\hline & UMA222 & GTA AGT GCA GCA TTA AAT TCA ATG & & \\
\hline \multirow{2}{*}{ U. parvum serovar 1} & UMS83 & TACTGATAGAAATTATGTAAGATTGC & \multirow{2}{*}{398} & \\
\hline & UMA269' & CCAAATGACCTTTTGTAACTAGAT & & {$[5]$} \\
\hline \multirow{2}{*}{ U. parvum serovar 6} & UMS54 & CTTAGTGTTCATATTTTTTACTAG & \multirow{2}{*}{369} & [5] \\
\hline & UMA269' & CCAAATGACCTTTTGTAACTAGAT & & \\
\hline \multirow{2}{*}{ U. parvum serovar $3 / 14$} & UMS125 & GTATTTGCAATCTTTATATGTTTTCG & \multirow{2}{*}{442} & \\
\hline & UMA269 & CTAAATGACCTTTTTCAAGTGTAC & & \\
\hline
\end{tabular}

and 14) and $U$. urealyticum (biovar T960T) is separated on three subtypes. Subtype 1 includes serovars 2, 5, 8, and 9; subtype 2 comprises serovars $4,10,12$, and 13; and subtype 3 contains serovars 7 and 11. A Polishian study showed that infection of the upper genitourinary tract with U. parvum is more common in infertile women than in fertile women [2]. Several studies suggest that the pathogenicity of Ureaplasma may be serotype-dependent, and others have shown that some serotypes are more frequently associated with syndromes than others [8-10]. U. parvum serovar 3 is the most frequently detected in infertile women and men, and some studies have revealed that the infiltration of $U$. parvum serovars 1,3 , and 6 caused morphological changes of the external genitalia in female mice, which can cause disorders of the superior genital tract that can lead to infertility [11]. However, $U$. parvum serovar 6 is the second most prevalent (in both women and men) and is associated with premature birth [12-14]. It is the leading cause of death among children under five years in developing countries [15].

In Morocco, there is no information about Ureaplasma biovars prevalence, serovars distribution of U. parvum, and their association with the risk factors and genital sexually transmitted infection- (STI-) related symptoms.

The present study aims at determining the prevalence of Ureaplasma biovars and U. parvum serovars, their associated risk factors, and genital STI- related symptoms.

\section{Materiel and Methods}

2.1. Patients and Sampling. A prospective study was conducted from 2013 to 2015 among women attending the Department of Obstetrics and Gynecology and the Laboratory of Pathological Anatomy of Hassan II University Hospital of Fez, Morocco, to determine the prevalence of bacterial STI and to characterize species [16]. All collected cervical samples were used to determine the prevalence of Ureaplasma biovars and to subtype U. parvum. All demographics and clinical data of the patients are available. Patients were divided in two groups, asymptomatic women who came to the gynecological examination because of a routine checkup and symptomatic women who had at least one of the following symptoms: leucorrhoea, pelvic pain/dyspareunia, pruritus, menorrhagia, metrorrhagia, or dysuria.
2.2. Ethics. The study was approved by the Institutional Review Board of Fez, Morocco (No. 02/15), and a written consent was obtained from all women.

2.3. Ureaplasma Biovars Detection and U. parvum Subtyping. $U$. urealyticum and $U$. parvum were detected in cervical samples by PCR using UreaA-B (F and R) and UMS-57/UMA222 primers, respectively, as described previously [5, 17]. The samples that were U. parvum positives were further typed, and their serovars were determined using a previously described PCR targeting the $m b a$ (multiband antigen) gene [5]. The specific primer pairs used as well as the size of the generated products were described in Table 1.

2.4. Statistical Analysis. Statistical analysis was performed using the SPSS (version 20) software. The different correlations were made using the chi-squared or Fisher's exact tests. The multivariate analysis was carried by binary logistic regression to determine the risk factors including all the variables with $P \leq 0.20$ in the initial model. The results were expressed as odds ratio (OR), 95\% confidence intervals (CIs), and $P$ values. In all tests, a $P$ value $<0.05$ was considered as significant.

\section{Results}

3.1. Description of the Study Population. A total of 1053 patients were included in this study. The recruited participants were aged between 18 and 85 years (median age 42 years). Among these women, 29\% (302/1053) are menopaused and $19 \%(197 / 1053)$ are pregnant. Of the 1053 women enrolled in the study, 39\% (409/1053) were presented genital STI-related symptoms. The most common symptoms were leucorrhoea $(32.3 \% ; 132 / 409)$, pelvic pain/dyspareunia $(26.6 \% ; 109 / 409)$, pruritus $(19.3 \% ; 79 / 409)$, metrorrhagia $(14 \% ; 57 / 409)$, dysuria $(4.6 \% ; 19 / 409)$, and menorrhagia (3.2\%; 13/409). Moreover, more than half (61\%) (644/1053) of the participants had no genital STI-related symptoms. The socio-demographics and clinical characteristics of the study population are presented in Table 2 .

3.2. Prevalence and Distribution of Ureaplasma Biovars and U. parvum Serovars. Of the 1053 women examined, $25.4 \%$ (268/1053) were Ureaplasma positives. The rates of $U$. 
TABLE 2: The socio-demographics and clinical characteristics of the study population.

\begin{tabular}{|c|c|c|}
\hline Variable & $N$ & $\%$ \\
\hline \multicolumn{3}{|c|}{ Area, $n=1035$} \\
\hline Rural & 212 & 20.5 \\
\hline Urban & 823 & 79.5 \\
\hline \multicolumn{3}{|c|}{ Age (years), $n=1047$} \\
\hline$<30$ & 167 & 16 \\
\hline $30-50$ & 624 & 59.5 \\
\hline$>50$ & 256 & 24.5 \\
\hline \multicolumn{3}{|c|}{ Menopause, $n=1033$} \\
\hline No & 731 & 70.8 \\
\hline Yes & 302 & 29.2 \\
\hline \multicolumn{3}{|c|}{ Education level, $n=1038$} \\
\hline Illiterate & 657 & 63.3 \\
\hline Literate & 381 & 36.7 \\
\hline \multicolumn{3}{|c|}{ Number of pregnancies, $n=1037$} \\
\hline$\leq 4$ & 724 & 69.8 \\
\hline$>4$ & 313 & 30.2 \\
\hline \multicolumn{3}{|c|}{ Parity, $n=1038$} \\
\hline$\leq 4$ & 832 & 80.2 \\
\hline$>4$ & 206 & 19.8 \\
\hline \multicolumn{3}{|c|}{ Passive smoking, $n=1031$} \\
\hline No & 785 & 76.1 \\
\hline Yes & 246 & 23.9 \\
\hline \multicolumn{3}{|c|}{ Oral contraception, $n=1030$} \\
\hline No & 722 & 76.1 \\
\hline Yes & 246 & 23.9 \\
\hline \multicolumn{3}{|c|}{ Age at 1st sexual intercourse (years), $n=1031$} \\
\hline$\leq 20$ & 656 & 63.6 \\
\hline$>20$ & 375 & 36.4 \\
\hline \multicolumn{3}{|c|}{ Number of lifetime sexual partners, $n=1028$} \\
\hline 1 & 974 & 94.7 \\
\hline$\geq 1$ & 54 & 5.3 \\
\hline \multicolumn{3}{|c|}{ Pregnancy status } \\
\hline No & 856 & 81 \\
\hline Yes & 197 & 19 \\
\hline \multicolumn{3}{|c|}{ Presence of genital STI-related symptoms } \\
\hline No & 644 & 61 \\
\hline Yes & 409 & 39 \\
\hline \multicolumn{3}{|l|}{ Infertility } \\
\hline No & 1006 & 95.5 \\
\hline Yes & 47 & 4.5 \\
\hline
\end{tabular}

urealyticum and $U$. parvum were $12.1 \%$ (128/1053) and $7 \%$ (74/1053), respectively, and both biovars were present in $6.3 \%(66 / 1053)$ cases. Considering the mixed infection/colonization, the prevalence of $U$. urealyticum was $18 \%$ (194/1053), and that of U. parvum was $13 \%(140 / 1053)$.

The $U$. parvum typing shows that the serovar $3 / 14$ was the most frequent $(80 / 140,57.1 \%)$, followed by the serovar

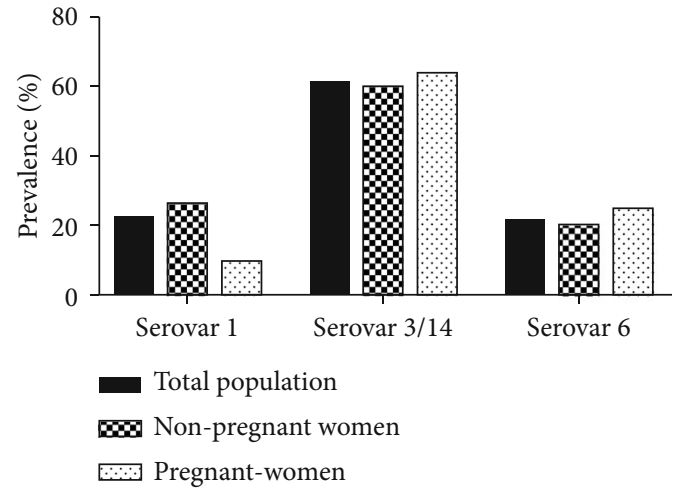

Figure 1: Distribution of U. parvum serovars in the study population.

1 and the serovar $6(20 \%, 28 / 140$ and $17.9 \%, 25 / 140$, respectively). This distribution was different when considering the pregnant women only. Thus, the serovar $3 / 14$ is still the most predominant $(64.5 \%)$ followed by serovar $6(25.8 \%)$ and then the serovar 1 (9.7\%) (Figure 1).

The presence of multiple serovars was noted in seven cases $5 \%(7 / 140)$ with a predominance of two serovars in six cases $4.3 \%(6 / 140)$ [Two cases (serovar 1 and serovar $3 / 14$ ), three cases (serovar 3/14 and serovar 6), and one case (serovar 1 and serovar 6)] and a single case of triple serovar $0.7 \%(1 / 40)$. These coinfection/colonization serovars were detected only in nonpregnant women.

3.3. Risk Factors Associated with Ureaplasma Biovars and U. parvum Serovars. To determine the risk factors associated with Ureaplasma biovars and U. parvum serovars, a univariate analysis was performed by excluding the mixed cases of U. urealyticum/U. parvum $(N=66)$ and $U$. parvum serovars $(N=7)$.

Variables used for this analysis include sociodemographic factors, medical history, and sexual behaviour. The results of this analysis are presented in Table 3.

The correlation of Ureaplasma biovars and U. parvum serovars to the age shows that Ureaplasma spp., U. urealyticum, and $U$. parvum serovar $3 / 14$ had a peak of prevalence in women " $<30$ " years-old. However, U. parvum serovar 6 was found maximally in the "30-50" years-old women and $U$. parvum serovar lwas more frequent in the " $>50$ " yearsold age group (Figure 2). Thus, the univariate analysis shows a significant association between Ureaplasma and " $<30$ " years of age $(P=0.048)$ (Table 3$)$.

All the variables with $P$ value $\leq 0.2$ were used in a multivariate analysis, and the results are presented in Table 4. Age (“<30" years) seems to be a risk factor of Ureaplasma spp. and U. urealyticum carriage (OR 1.729, 95\% CI [1.1132.687] and OR 1.848, 95\% CI [1.026-3.330], respectively).

3.4. Correlation between Ureaplasma Biovars and U. parvum Serovars and Genital STI-Related Symptoms. In order to study the correlation between genital STIs-related symptoms and Ureaplasma biovars, a statistical analysis was performed. For this analysis, Ureaplasma negative cases and the coinfection of Ureaplasma spp. with other STI (Human 
TABLE 3: Prevalence of Ureaplasma biovars according to different variables.

\begin{tabular}{|c|c|c|c|c|c|}
\hline Characteristics & $\begin{array}{l}\text { Number total of } \\
\text { participants }\end{array}$ & $\begin{array}{c}\text { U. urealyticum } \\
\text { (positive) }(N=128)\end{array}$ & $\begin{array}{c}U . \text { parvum } \\
\text { (positive) }(N=74)\end{array}$ & $\begin{array}{l}\text { U. urealyticum/U. parvum } \\
\quad \text { (positive) }(N=66) \\
n(\%)\end{array}$ & $\begin{array}{c}\text { Ureaplasma spp. } \\
\text { (positive) }(N=268)\end{array}$ \\
\hline \multicolumn{6}{|l|}{ Area } \\
\hline Rural & 212 & $26(12.3)$ & $14(6.6)$ & $18(8.5)$ & $58(27.4)$ \\
\hline Urban & 823 & $100(12.2)$ & $59(7.2)$ & $48(5.8)$ & $207(25.2)$ \\
\hline$P$ & & 0.96 & 0.774 & 0.158 & 0.512 \\
\hline \multicolumn{6}{|c|}{ Age group (years) } \\
\hline$<30$ & 167 & $27(16.2)$ & $11(6.6)$ & $16(9.6)$ & $54(32.3)$ \\
\hline $30-50$ & 624 & $76(12.2)$ & $47(7.5)$ & $35(5.6)$ & $158(25.3)$ \\
\hline$>50$ & 254 & $24(9.4)$ & $16(6.3)$ & $15(5.9)$ & $55(21.7)$ \\
\hline$P$ & & 0.119 & 0.782 & 0.165 & 0.048 \\
\hline \multicolumn{6}{|l|}{ Menopause } \\
\hline No & 731 & $97(13.3)$ & $49(6.7)$ & $49(6.7)$ & $195(26.7)$ \\
\hline Yes & 302 & $29(9.6)$ & $22(7.3)$ & $17(5.6)$ & $68(22.5)$ \\
\hline$P$ & & 0.101 & 0.737 & 0.521 & 0.163 \\
\hline \multicolumn{6}{|l|}{ Education level } \\
\hline Illiterate & 657 & $83(12.6)$ & $44(6.7)$ & $42(6.4)$ & $169(25.7)$ \\
\hline Literate & 381 & $43(11.3)$ & $29(7.6)$ & $24(6.3)$ & $96(25.2)$ \\
\hline$P$ & & 0.522 & 0.579 & 0.953 & 0.851 \\
\hline \multicolumn{6}{|c|}{ Number of pregnancies } \\
\hline$\leq 4$ & 724 & $94(13.0)$ & $45(6.2)$ & $50(6.9)$ & $189(26.1)$ \\
\hline$>4$ & 313 & $32(10.2)$ & $28(8.9)$ & $16(5.1)$ & $76(24.3)$ \\
\hline$P$ & & 0.212 & 0.115 & 0.277 & 0.536 \\
\hline \multicolumn{6}{|l|}{ Parity } \\
\hline$\leq 4$ & 832 & $104(12.5)$ & $57(6.9)$ & $56(6.7)$ & $217(26.1)$ \\
\hline$>4$ & 206 & $22(10.7)$ & $16(7.8)$ & $10(4.9)$ & $48(23.3)$ \\
\hline$P$ & & 0.474 & 0.645 & 0.323 & 0.413 \\
\hline \multicolumn{6}{|l|}{ Passive smoking } \\
\hline No & 785 & $94(12.0)$ & $58(7.4)$ & $56(7.1)$ & $208(26.5)$ \\
\hline Yes & 246 & $31(12.6)$ & $15(6.1)$ & $10(4.1)$ & $56(22.8)$ \\
\hline$P$ & & 0.793 & 0.491 & 0.086 & 0.242 \\
\hline \multicolumn{6}{|c|}{ Oral contraception } \\
\hline No & 722 & $89(12.3)$ & $52(7.2)$ & $48(6.6)$ & $189(26.2)$ \\
\hline Yes & 308 & $37(12.0)$ & $21(6.8)$ & $18(5.8)$ & $76(24.7)$ \\
\hline$P$ & & 0.888 & 0.826 & 0.630 & 0.614 \\
\hline \multicolumn{6}{|c|}{$\begin{array}{l}\text { Age at 1st sexual } \\
\text { intercourse (years) }\end{array}$} \\
\hline$\leq 20$ & 656 & $84(12.8)$ & $47(7.2)$ & $36(5.5)$ & $167(25.5)$ \\
\hline$>20$ & 375 & $42(11.2)$ & $26(6.9)$ & $30(8.0)$ & $98(26.1)$ \\
\hline$P$ & & 0.449 & 0889 & 0.113 & 0.811 \\
\hline \multicolumn{6}{|c|}{$\begin{array}{l}\text { Number of lifetime } \\
\text { sexual partners }\end{array}$} \\
\hline 1 & 974 & $122(12.5)$ & $68(7.0)$ & $60(6.2)$ & $250(25.7)$ \\
\hline$\geq 1$ & 54 & $4(7.4)$ & $5(9.3)$ & $6(11.1)$ & $15(27.8)$ \\
\hline$P$ & & 0.264 & 0.336 & 0.126 & 0.730 \\
\hline
\end{tabular}

$P$ value, $\chi^{2}$, or Fisher's exact test. 

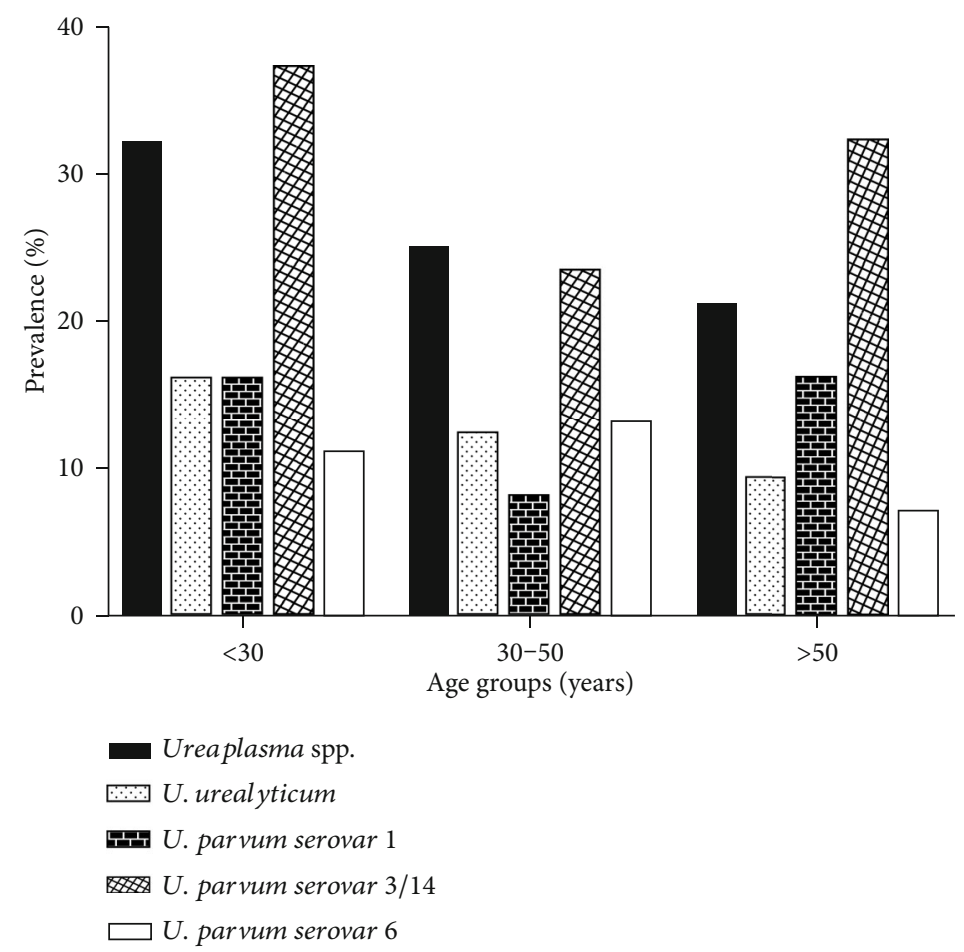

FIGURE 2: Prevalence of Ureaplasma biovars and U. parvum serovars according to participant's age.

TABLE 4: Risk factors associated with Ureaplasma biovars (multivariate analysis).

\begin{tabular}{|c|c|c|c|c|c|}
\hline \multicolumn{3}{|c|}{ Variables } & \multirow{2}{*}{$\begin{array}{c}\text { Odds ratio } \\
1.729\end{array}$} & \multirow{2}{*}{$\begin{array}{c}95 \% \text { CI } \\
1.113-2.687\end{array}$} & \multirow{2}{*}{$\begin{array}{c}P \text { value } \\
0.015\end{array}$} \\
\hline & & $<30$ & & & \\
\hline \multirow[t]{3}{*}{ Ureaplasma spp. } & Age (years) & $30-50$ & 1.227 & $0.865-1.739$ & 0.251 \\
\hline & & $>50$ & 1 & - & - \\
\hline & & $<30$ & 1.848 & $1.026-3.330$ & 0.041 \\
\hline \multirow[t]{2}{*}{ U. urealyticum } & Age (years) & $30-50$ & 1.329 & $0.819-2.157$ & 0.249 \\
\hline & & $>50$ & 1 & - & - \\
\hline
\end{tabular}

TABLE 5: Correlation between Ureaplasma biovars with clinical symptomatology and infertility.

\begin{tabular}{lccc}
\hline & \multicolumn{3}{c}{ Ureaplasma biovars } \\
& U. urealyticum, & U. parvum, & \\
& & $n(\%)$ & \\
& & & \\
\hline $\begin{array}{l}\text { Genital STI-related } \\
\text { symptoms } \\
\text { Yes, } N=36\end{array}$ & $19(52.8)$ & $17(47.2)$ & 0.869 \\
No, $N=51$ & $26(51.0)$ & $25(49.0)$ & \\
Infertility & & & \\
Yes, $N=5$ & $2(40.0)$ & $3(60.0)$ & 0.591 \\
No, $N=82$ & $43(52.4)$ & $39(47.6)$ & \\
\hline
\end{tabular}

$P$ value, $\chi^{2}$, or Fisher's exact test.

papillomavirus, Chlamydia trachomatis, Neisseria gonororhea, Mycoplasma genitalium, and Mycoplasma hominis) cases were excluded. Therefore, only 87 Ureaplasma cases were considered (45 and 42 cases of $U$. urealyticum and $U$. parvum, respectively). The results of correlations were presented in Table 5. Thus, 36 women were with genital STI-related symptoms vs. 51 of asymptomatic women, and 5 women were infertile vs. 82 of fertile women. U. urealyticum and U. parvum were equally distributed among symptomatic and asymptomatic patients. However, a higher frequency of $U$. parvum was observed in infertile women (Table 5).

To determine the correlation between the presence of genital STI-related symptoms and U. parvum serovars, cases with multiples serovars $(N=7)$ were excluded. The results were presented in Table 6 . The results show a significant association between $U$. parvum serovar 1 and infertility $(P=0.011)$ (Table 6).

\section{Discussion}

Ureaplasma spp. mainly resides on the mucous surfaces of the urogenital tract in adults or in the respiratory tract of 
TABLE 6: Correlation between $U$. parvum serovars with clinical symptomatology and infertility.

\begin{tabular}{|c|c|c|c|}
\hline & \multicolumn{3}{|c|}{ U. parvum serovars } \\
\hline & $\begin{array}{l}\text { Serovar } 1 \\
\quad N=6\end{array}$ & $\begin{array}{c}\text { Serovar } 3 / 14, \\
\quad N=30 \\
n(\%)\end{array}$ & $\begin{array}{c}\text { Serovar } 6 \\
\quad N=3\end{array}$ \\
\hline \multicolumn{4}{|c|}{$\begin{array}{l}\text { Genital STI-related } \\
\text { symptoms }\end{array}$} \\
\hline Yes, $N=17$ & $1(5.9)$ & $15(88.2)$ & $1(5.9)$ \\
\hline No, $N=22$ & $5(22.7)$ & $15(68.2)$ & $2(9.1)$ \\
\hline$P$ value & 0.154 & 0.146 & 0.713 \\
\hline \multicolumn{4}{|l|}{ Infertility } \\
\hline Yes, $N=3$ & $2(66.7)$ & $1(33.3)$ & $0(0)$ \\
\hline No, $N=36$ & $4(11.1)$ & $29(80.6)$ & $3(8.3)$ \\
\hline$P$ value & 0.011 & 0.066 & 0.607 \\
\hline
\end{tabular}

infants [18]. These species can be responsible of nongonococcal urethritis and pregnancy complications. Their incidence is higher in women compared to men [19], and their colonization was related to age, low socio-economic level, multiplicity of sexual partners, ethnicity, and oral contraceptives uses [20].

To the best of our knowledge, this is the first study conducted in Morocco with the aim at determining the distribution, the prevalence of Ureaplasma biovars and the circulating $U$. parvum serovars, and their association with risk factors and genital STI-related symptoms.

The present study shows that $25 \%$ of women harbored Ureaplasma spp. This rate is slightly similar to that obtained in an Italian study (23\%) [21], but lower than the rate obtained in Croatian study (34\%) [3] (Table 7). Nevertheless, in the Italian study, the obtained prevalence represents only cases of Ureaplasma culture-positive with a bacterial load of $\geq 10^{4} \mathrm{CFU}$ (infection cases). This can explain the low rate obtained compared to our results, where $U$. urealyticum detection has been made directly by PCR without bacterial quantification.

Regarding Ureaplasma biovars, our results showed a predominance of $U$. urealyticum $(18 \%$; 194/1053) compared to U. parvum (13\%; 140/1053) (considering the mixed infection/colonization). This distribution seems to be inversed compared to that reported on other geographical area such as in Italia and Croatia $[3,21]$. The U. parvum subtyping results show that $U$. parvum serovar $3 / 14$ was the most prevalent followed by serovars 1 and 6 , respectively. Similar distribution was observed in the Italian study even if the rates are different [21] (Table 7). The study population and geographic location can explain this difference.

In nonpregnant women group and independently of their fertility status, the prevalence of $U$. urealyticum and $U$. parvum was $11.6 \%(99 / 856)$ and $6.8 \%$ (58/856), respectively (excluding cases of mixed detection). These distribution and prevalence are different from that reported in a Brazilian study, which was marked by high prevalence of $U$. parvum $(60.6 \%)$ [22] (Table 7). The difference is notably observed at $U$. parvum serovar distribution level and was marked
[22], in comparison with our result, by the lowest rate of serovar 1 and higher cases of coinfection/colonization [22] (Table 7). This difference may be related to geographic area, sample size, and the sexual activity.

In pregnant women group, the $U$. urealyticum is more predominant than $U$. parvum $(14.7 \%(29 / 197)$ vs. $8.1 \%$ $(16 / 197)$ ), respectively (and considering simple infection/colonization only), inversely to results obtained on Australian women [14] (Table 7). The difference was also obtained in $U$. parvum type distribution that even if the serovar $3 / 14$ is predominant in both populations, the serovar 1 is largely prevalent than serovar 6 in the Australian study [5] (Table 7). Nevertheless, our serovars distribution is similar to that recently obtained in an American and another Australian studies (where serovars 3 and 6 are the most frequent) $[14,23]$ (Table 7). This can raises the question of epidemiological evolution or changes of species distribution over the time. The fact that in these later studies, serovar 6 was significantly associated with preterm delivery $[14,23]$ lets us suppose that pregnant women of our series, carrying serovar $6(25.8 \%)$, were probably at risk of premature delivery. Thus, it is necessary to supervise their pregnancy progress in order to verify this hypothesis and to strengthen screening programs for Ureaplasma to prevent complications.

In our study, the presence of multiple $U$. parvum serovars was not detected in the group of pregnant women while it was reported in $8 \%$ and $2.8 \%$ of cases in Australian studies $[5,14]$ (Table 7). This difference may be related to the geographic location and sexual behaviors of women as well as that of their partners.

The correlation between $U$. parvum serovars and age has been studied and the results show that high levels of $U$. parvum serovar 3/14 and serovar 6 were mainly obtained in young women " $\leq 50$ years" (which can be related to sexual activity), while the $U$. parvum serovar 1 was more common among women aged " $>50$ " years. This can be related to the hormonal status (menopause) of these women as reported by Iwasaka et al. who described the presence of Ureaplasma spp. in vaginal flora of $25 \%$ of postmenopausal women [24]. In fact, menopause may be associated with vaginal atrophy, thinning of the vaginal wall, dryness, and changes in $\mathrm{pH}$ due to a lack of estrogen, factors that may affect sexual function, and promotes infection/colonization [25].

Using logistic regression models, a significant association was obtained between the age group " $<30$ years" and Ureaplasma spp. $(P=0.048)$. These results are not surprising and confirm the results of previous studies $[26,27]$ as well as the fact that genital mycoplasmas are linked to sexual activity. In our series, most of the recruited patients declared that they had only one sexual partner during their life (their husband) which is related to socio-cultural and religious context. Thus, the association between sexual behavior and Ureaplasma biovars cannot be performed.

The correlation between Ureaplasma biovars and genital STI-related symptoms shows no association neither for $U$. parvum nor for $U$. urealyticum. These results are consistent with those of other studies conducted in Australia, Slovenia, and Croatia $[3,28,29]$. However, an Italian study reported that $U$. urealyticum and $U$. parvum serovar $3 / 14$ were 


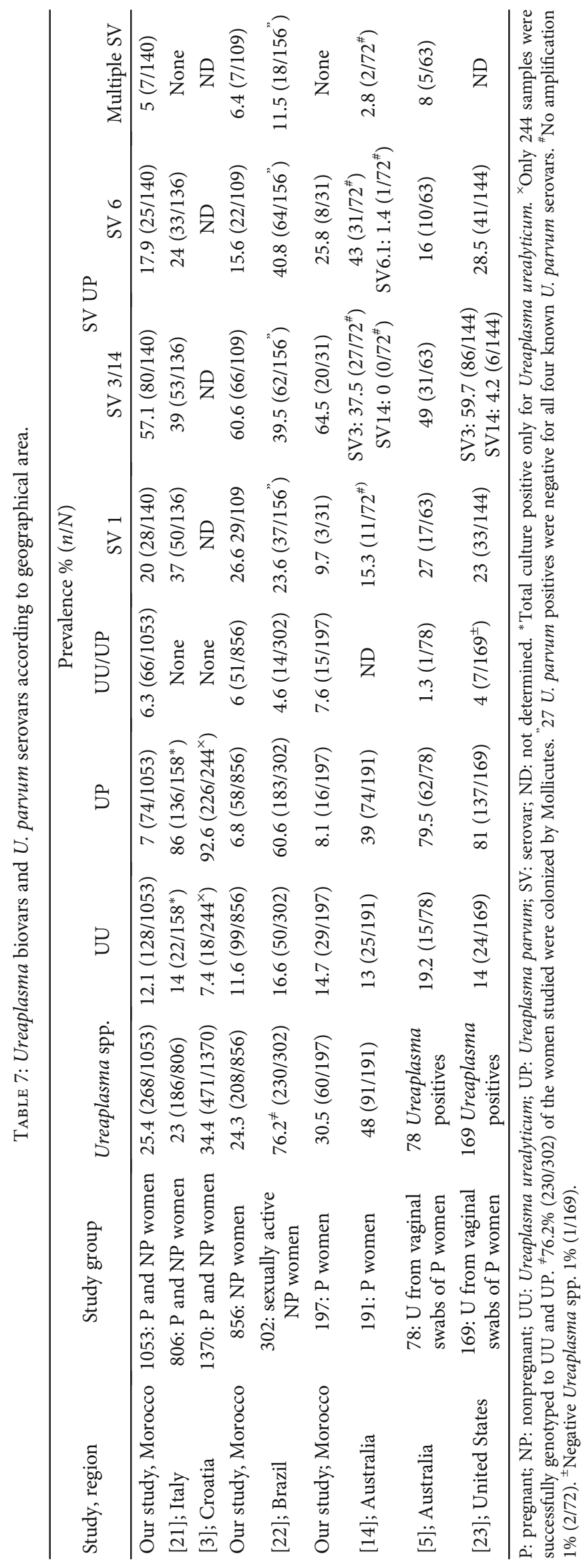


significantly associated with symptomatic patients [21]. In our study, a significant association between $U$. parvum serovar 1 and infertility was obtained $(P=0.011)$. To confirm this data, the study of larger population and refinement of Ureaplasma spp. molecular characterization will be of interest.

There were some limitations of the present study: firstly, the patients participating in this study may not be truly representative of the Moroccan population; in other words, the data derived from this region may not reflect the situation of other geographical regions and studies in the other Moroccan regions are required. Secondly, following the successive recruitment of patients, the sample size in the groups of asymptomatic and symptomatic women was different. Likewise, the cultivation and quantification of Ureaplasma spp. were not carried out. Therefore, simple colonization cannot be distinguished from infection. However, our main objective was to determine the prevalence of Ureaplasma biovars and U. parvum serovars, their associated risk factors, and genital STI-related symptoms.

\section{Conclusion}

In this study, the distribution and prevalence of Ureaplasma biovars and each of the $U$. parvum serovars have been determined. Thus, the results showed the predominance of $U$. urealyticum compared to $U$. parvum. Moreover, the $U$. parvum subtyping revealed that the serovar $3 / 14$ is the most prevalent followed by serovars 1 and 6 and a significant association between serovar 1 and infertility. This lets suggest the need of testing this species in the infertility cases.

The obtained results provide an idea on Ureaplasma biovars and $U$. parvum serovars distribution in Morocco and especially in Fez region area, their associated risk factors, and genital STI-related symptoms. Further studies are needed to clarify and confirm the pathogenic role of these species.

\section{Data Availability}

The data used to support the findings of this study are available from the corresponding author upon request.

\section{Ethical Approval}

This study was approved by the Institutional Review Board of Fez, Morocco (No. 02/15).

\section{Conflicts of Interest}

The authors declare that there are no conflicts of interest regarding the publication of this paper.

\section{Acknowledgments}

We would like to thank the staff of the Obstetrics and Gynecology Department and the Anatomo-Pathology Laboratory of CHU Hassan II of Fez for their help in clinical examination and the specimen collection, respectively.

\section{References}

[1] B. Dhawan, N. Malhotra, V. Sreenivas et al., "Ureaplasma serovars \& their antimicrobial susceptibility in patients of infertility \& genital tract infections," The Indian Journal of Medical Research, vol. 136, no. 6, pp. 991-996, 2012.

[2] K. Urszula, E. Joanna, E. Marek, M. Beata, and S. B. Magdalena, "Colonization of the lower urogenital tract with Ureaplasma parvum can cause asymptomatic infection of the upper reproductive system in women: a preliminary study," Archives of Gynecology and Obstetrics, vol. 289, no. 5, pp. 1129-1134, 2014.

[3] B. Hunjak, I. Sabol, G. Vojnović et al., "Ureaplasma urealyticum and Ureaplasma parvum in women of reproductive age," Archives of Gynecology and Obstetrics, vol. 289, no. 2, pp. 407-412, 2014.

[4] D. Taylor-Robinson, "Mollicutes in vaginal microbiology: Mycoplasma hominis, Ureaplasma urealyticum, Ureaplasma parvum and Mycoplasma genitalium," Research in Microbiology, vol. 168, no. 9-10, pp. 875-881, 2017.

[5] F. Kong, Z. Ma, G. James, S. Gordon, and G. L. Gilbert, "Species identification and subtyping of Ureaplasma parvum and Ureaplasma urealyticum using PCR-based assays," Journal of Clinical Microbiology, vol. 38, no. 3, pp. 1175-1179, 2000.

[6] T. Deguchi, T. Yoshida, T. Miyazawa et al., "Association of Ureaplasma urealyticum (biovar 2) with nongonococcal urethritis," Sexually Transmitted Diseases, vol. 31, no. 3, pp. 192-195, 2004.

[7] E. L. Sweeney, S. J. Dando, S. G. Kallapur, and C. L. Knox, "The human Ureaplasma species as causative agents of chorioamnionitis," Clinical Microbiology Reviews, vol. 30, no. 1, pp. 349-379, 2017.

[8] F. Grattard, B. Soleihac, B. De Barbeyrac, C. Bebear, P. Seffert, and B. Pozzetto, "Epidemiologic and molecular investigations of genital mycoplasmas from women and neonates at delivery," The Pediatric Infectious Disease Journal, vol. 14, no. 10, pp. 853-858, 1995.

[9] A. Naessens, W. Foulon, J. Breynaert, and S. Lauwers, "Serotypes of Ureaplasma urealyticum isolated from normal pregnant women and patients with pregnancy complications," Journal of Clinical Microbiology, vol. 26, no. 2, pp. 319-322, 1988.

[10] J. A. Robertson, L. H. Honore, and G. W. Stemke, "Serotypes of Ureaplasma urealyticum in spontaneous abortion," Pediatric Infectious Disease, vol. 5, Supplement, pp. S270-S272, 1986.

[11] G.-X. Zhu, C. Lu, C.-J. Chen et al., "Pathogenicity of Ureaplasma urealyticum and Ureaplasma parvum in the lower genital tract of female BALB/c mice," Canadian Journal of Microbiology, vol. 57, no. 12, pp. 987-992, 2011.

[12] S. Kataoka, T. Yamada, K. Chou et al., "Association between preterm birth and vaginal colonization by mycoplasmas in early pregnancy," Journal of Clinical Microbiology, vol. 44, no. 1, pp. 51-55, 2006.

[13] M. Mitsunari, S. Yoshida, I. Deura et al., "Cervical Ureaplasma urealyticum colonization might be associated with increased incidence of preterm delivery in pregnant women without prophlogistic microorganisms on routine examination," Journal of Obstetrics and Gynaecology Research, vol. 31, no. 1, pp. 16-21, 2005.

[14] M. S. Payne, D. J. Ireland, R. Watts et al., "Ureaplasma parvum genotype, combined vaginal colonisation with Candida albicans, and spontaneous preterm birth in an Australian cohort 
of pregnant women," BMC Pregnancy and Childbirth, vol. 16, no. 1, p. 312, 2016.

[15] H. Blencowe, S. Cousens, M. Z. Oestergaard et al., "National, regional, and worldwide estimates of preterm birth rates in the year 2010 with time trends since 1990 for selected countries: a systematic analysis and implications," Lancet, vol. 379, no. 9832, pp. 2162-2172, 2012.

[16] S. Karim, C. Bouchikhi, A. Banani et al., "Molecular antimicrobial resistance of Neisseria gonorrhoeae in a Moroccan area," Infectious Diseases in Obstetrics and Gynecology, vol. 2018, 11 pages, 2018.

[17] S. R. Lee, J. M. Chung, and Y. G. Kim, "Rapid one step detection of pathogenic bacteria in urine with sexually transmitted disease (STD) and prostatitis patient by multiplex PCR assay (MPCR)," Journal of Microbiology, vol. 45, no. 5, pp. 453459, 2007.

[18] K. B. Waites, L. Xiao, V. Paralanov, R. M. Viscardi, and J. I. Glass, "Molecular methods for the detection of mycoplasma and Ureaplasma infections in humans," The Journal of Molecular Diagnostics, vol. 14, no. 5, pp. 437-450, 2012.

[19] K. B. Waites and L. Xiao, "Mycoplasmas and Ureaplasmas of humans," in Molecular Medical Microbiology, pp. 1587-1609, 2015.

[20] G. H. Cassell, K. B. Waites, H. L. Watson, D. T. Crouse, and R. Harasawa, "Ureaplasma urealyticum intrauterine infection: role in prematurity and disease in newborns," Clinical Microbiology Reviews, vol. 6, no. 1, pp. 69-87, 1993.

[21] M. A. Francesco, R. Negrini, G. Pinsi, L. Peroni, and N. Manca, "Detection of Ureaplasma biovars and polymerase chain reaction-based subtyping of Ureaplasma parvum in women with or without symptoms of genital infections," European Journal of Clinical Microbiology \& Infectious Diseases, vol. 28, no. 6, pp. 641-646, 2009.

[22] T. N. Lobão, G. B. Campos, N. N. Selis et al., "Ureaplasma urealyticum and $\mathrm{U}$. parvum in sexually active women attending public health clinics in Brazil," Epidemiology and Infection, vol. 145, no. 11, pp. 2341-2351, 2017.

[23] L. Xiao, V. Paralanov, J. I. Glass et al., "Extensive horizontal gene transfer in Ureaplasmas from humans questions the utility of serotyping for diagnostic purposes," Journal of Clinical Microbiology, vol. 49, no. 8, pp. 2818-2826, 2011.

[24] T. Iwasaka, T. Wada, Y. Kidera, and H. Sugimori, "Hormonal status and mycoplasma colonization in the female genital tract," Obstetrics and Gynecology, vol. 68, no. 2, pp. 263-266, 1986.

[25] J. W. Honour, "Biochemistry of the menopause," Annals of Clinical Biochemistry: International Journal of Laboratory Medicine, vol. 55, no. 1, pp. 18-33, 2017.

[26] D. Domingues, L. Távora Tavira, A. Duarte, A. Sanca, E. Prieto, and F. Exposto, "Genital mycoplasmas in women attending a family planning clinic in Guiné-Bissau and their susceptibility to antimicrobial agents," Acta Tropica, vol. 86, no. 1, pp. 19-24, 2003.

[27] M. Magaña-Contreras, A. Contreras-Paredes, A. ChavezBlanco, M. Lizano, Y. De la Cruz-Hernandez, and E. De la Cruz-Hernandez, "Prevalence of sexually transmitted pathogens associated with HPV infection in cervical samples in a Mexican population," Journal of Medical Virology, vol. 87, no. 12, pp. 2098-2105, 2015.
[28] M. Marovt, D. Keše, T. Kotar et al., "Ureaplasma parvum and Ureaplasma urealyticum detected with the same frequency among women with and without symptoms of urogenital tract infection," European Journal of Clinical Microbiology \& Infectious Diseases, vol. 34, no. 6, pp. 1237-1245, 2015.

[29] M. L. McKechnie, R. J. Hillman, R. Jones et al., “The prevalence of urogenital micro-organisms detected by a multiplex PCRreverse line blot assay in women attending three sexual health clinics in Sydney, Australia," Journal of Medical Microbiology, vol. 60, no. 7, pp. 1010-1016, 2011. 